\title{
EGF Receptor Activation Stimulates Endogenous Gastrin Gene Expression in Canine G Cells and Human Gastric Cell Cultures
}

\author{
Michael G. Ford, ${ }^{\star}$ John Del Valle, ${ }^{\star}$ Carol J. Soroka, ${ }^{\|}$and Juanita L. Merchant ${ }^{\star} §$ \\ $*$ Department of Internal Medicine, and ${ }^{\ddagger}$ Department of Physiology, University of Michigan; and the ${ }^{\S}$ Howard Hughes Medical \\ Institute, Ann Arbor, Michigan 48109-0650; and the "Department of Internal Medicine, Yale School of Medicine, New Haven, \\ Connecticut 06520-8019
}

\begin{abstract}
Gastrin release from the antral gastrin-expressing cell ( $\mathrm{G}$ cell) is regulated by bombesin and luminal factors. Yet, these same extracellular regulators do not stimulate expression of the gene. Since the gastric mucosa expresses large quantities of EGF receptor ligands such as TGF $\alpha$, we examined whether EGF receptor ligands stimulate gastrin gene expression in gastrin-expressing cell cultures. EGF receptor activation of primary cultures stimulated gastrin gene expression about twofold; whereas bombesin treatment of antral G cell cultures stimulated gastrin release but not gene expression. EGF and TGF $\alpha$ were weak stimulants of gastrin release. EGF receptor activation of AGS human gastric adenocarcinoma cell line stimulated gastrin gene expression nearly fourfold; and gastrin reporter constructs transfected into AGS cells were stimulated more than fourfold by EGF. EGF induction was conferred by the previously defined GC-rich gastrin EGF response element (gERE) element located at -68 to -53 bp upstream from the cap site since a mutation of the gERE element abolished both basal and EGF induction. Moreover, EGF treatment of AGS cells stimulated binding of the transcription factor $\mathrm{Sp} 1$ to this element. Collectively, these results demonstrate that gastrin gene expression and gastrin release are regulated by different signaling pathways: gene expression by EGF receptor activation and gastrin secretion by neuropeptides and luminal factors. (J. Clin. Invest. 1997. 99: 2762-2771.) Key words: gERE • gene expression • DNA element • Sp1 - TGF $\alpha$
\end{abstract}

\section{Introduction}

Gastrin release is regulated by changes in gastric $\mathrm{pH}$, cAMP, phorbol esters, bombesin, and amino acids (1-4). Proton pump inhibitors stimulate gastrin gene expression by inhibiting gastric acid secretion and by raising gastric $\mathrm{pH}(5,6)$. However, the specific regulators that mediate changes in gastrin gene expression in the antral $\mathrm{G}$ cell are not known. Nevertheless, since the gastric mucosa also expresses significant amounts of growth factors, it is possible that these ligands may regulate

Address correspondence to Juanita L. Merchant, M.D., Ph.D., 1150 West Medical Drive, MSRB I, 3510, Ann Arbor, MI 48109-0650. Phone: 313-647-2944; FAX: 313-936-1400; E-mail: merchanj@umich.edu

Received for publication 30 September 1996 and accepted in revised form 13 March 1997.

J. Clin. Invest.

(C) The American Society for Clinical Investigation, Inc. 0021-9738/97/06/2762/10 \$2.00

Volume 99, Number 11, June 1997, 2762-2771 the gastrin gene. Indeed, two recent animal studies have indicated that chronic EGF treatment stimulates gastrin secretion $(7,8)$. Although gastrin mRNA levels were not quantified, an increase in antral gastrin-expressing cell $(\mathrm{G} \text { cell })^{1}$ density was also shown, suggesting that the increase in serum gastrin levels was a result of increased synthesis (7).

Members of the EGF ligand family include EGF, TGFo, amphiregullin, betacellulin, heregulin, and heparin binding EGF (HB-EGF) that all share significant peptide homology and bind to the EGF receptor $(9,10)$. In particular, several of these ligands are expressed in the gastric antrum. TGF $\alpha$ and the EGF receptor are expressed in both fundic and antral mucosa (11). More recently, the EGF receptor and HB-EGF were colocalized to both the parietal and antral G cells, suggesting that these two gastric cell types are autoregulated by EGF receptor ligands (12). TGF $\alpha$ expression is localized primarily in parietal cells and surface mucous glands of the human stomach (13). However, EGF-expressing cells are not detected in healthy gastric mucosa, but instead appear in glands at the rims of peptic ulcers and Brunner's glands of the duodenum (13-15). An explanation for differences in the timing of EGF and TGF $\alpha$ expression in the stomach is not readily apparent since these two ligands are equipotent regulators of parietal cell function (16). Moreover, they also have similar binding affinities to the EGF receptor (17).

Recently, Yamada and co-workers (18) reported that EGF stimulates parietal cell $\mathrm{H}^{+}, \mathrm{K}^{+}$-ATPase gene expression at a lower concentration than required to inhibit acid secretion. In contrast, the effect of EGF receptor activation on antral $\mathrm{G}$ cell function is not known. Using stable transformants of a rat pituitary cell line expressing the human gastrin gene, we have shown previously that EGF and not gastrin-releasing peptide (GRP) stimulates gastrin gene expression (19). However, EGF regulation of gastrin has not been studied in native gastrinexpressing cells. Therefore, to study regulation of the gastrin gene in a native cell population, both primary canine $G$ cells and human gastric cell lines were treated with EGF or TGF $\alpha$. Changes in gastrin mRNA levels were analyzed by Northern blots and reverse transcriptase polymerase chain reaction (RTPCR). Stimulation of gastrin secretion by these same agonists was also examined in the primary culture system. We found that gastrin gene expression in canine antral cell cultures was stimulated by EGF receptor ligands but not by bombesin. In contrast, bombesin stimulated gastrin release, to a significantly greater degree than EGF or TGF $\alpha$. Increased expression of

1. Abbreviations used in this paper: $\mathrm{G}$ cell, antral gastrin-expressing cell; G-gly, glycine-extended progastrin; GAPDH, glyceraldehyde phosphate dehydrogenase; gERE, gastrin EGF response element; GRP, gastrin-releasing peptide; HB-EGF, heparin binding EGF; RTPCR, reverse transcriptase polymerase chain reaction. 
the endogenous gastrin gene in the AGS human gastric adenocarcinoma cell line was also stimulated by EGF receptor ligands. Using AGS cells stably transfected with gastrin reporter constructs, we found that EGF stimulates the gastrin promoter through the gastrin EGF response element (gERE) ( ${ }^{-68}$ GGGGCGGGGTGGGGGG) described previously (20). Thus, the results in both culture systems demonstrated that EGF receptor ligands increase gastrin gene expression.

\section{Methods}

Cell cultures and transfections. Primary canine G cell cultures were prepared by the Michigan Gastrointestinal Peptide Center using collagenase digestion and counterflow elutriation as described previously $(2,3)$. Approximately $6-8 \times 10^{6}$ cells were plated onto $100-\mathrm{mm}$ culture dishes precoated with Matrigel (Collaborative Research Inc., Lexington/Waltham, MA) in Dulbecco's MEM (GIBCO BRL, Gaithersburg, MD) containing $10 \%$ dog serum, $100 \mu \mathrm{g} / \mathrm{ml}$ penicillin, and $100 \mu \mathrm{g} / \mathrm{ml}$ streptomycin in a humidified atmosphere of $5 \% \mathrm{CO}_{2}$ and $95 \%$ air. The cells were allowed to settle for $24 \mathrm{~h}$. Nonadherent cells, mucous, and debris were removed by gentle tituration in PBS, and fresh medium without sera was added to each plate for $24 \mathrm{~h}$ before the addition of $10^{-8} \mathrm{M}$ TGF $\alpha, 10^{-8} \mathrm{M}$ EGF, or $10^{-7} \mathrm{M}$ bombesin. Total RNA was prepared $16 \mathrm{~h}$ after the administration of agonist. The resulting antral $\mathrm{G}$ cell cultures were a mixed population of epithelial cells and fibroblasts of which $15-25 \%$ were $\mathrm{G}$ cells by immunohistochemistry (2). The concentrations of agonists used here have been shown to maximally stimulate gastrin release or promoter activity $(3,19)$.

The AGS and MKN-45 cell lines (derived from human gastric adenocarcinomas) $(21,22)$ were cultured in Dulbecco's MEM containing $8 \%$ horse serum, $6 \%$ newborn calf serum, $100 \mu \mathrm{g} / \mathrm{ml}$ penicillin, and $100 \mu \mathrm{g} / \mathrm{ml}$ streptomycin in a humidified atmosphere of $5 \% \mathrm{CO}_{2}$ and $95 \%$ air. The AGS cells were stably transfected with the 240 GasLuc construct containing $240 \mathrm{bp}$ of the human gastrin promoter ligated upstream of the luciferase reporter in the pGL2B vector (Promega Corp., Madison, WI). A mutation of the gERE element within the 240 GasLuc construct was created using the site elimination method (23) and the mutant oligonucleotide ${ }^{5}$ ATGGCAGGGTAGGGGATTAGTGGGGGGACAGTTG as described previously (24). The four mutated nucleotides in the gERE sequence are underlined. Pooled stable transformants of AGS cells expressing the wildtype or mutant 240 GasLuc construct were created using calcium phosphate coprecipitation without glycerol shock (5 Prime-3 Prime, Inc., Boulder, $\mathrm{CO}$ ). The constructs were cotransfected in a 10:1 ratio with the pCMV neomycin plasmid and were selected in $400 \mu \mathrm{g} / \mathrm{ml}$ of G418 (GIBCO BRL). Since the basal luciferase activity of the stable transformants expressing the mutated gERE element was abolished, PCR analysis was used to verify stable incorporation of the plasmid into the genome. The same results were found in three pools of stable transformants created by separate transfections.

Gastrin peptide analysis. Medium was removed $2 \mathrm{~h}$ after the addition of agonist and then spun for $5 \mathrm{~s}$ at $16,000 \mathrm{~g}$ to remove cells and debris. The remaining adherent cells were lysed in $0.1 \mathrm{~N} \mathrm{NaOH}$, boiled for $5 \mathrm{~min}$, and centrifuged. The supernatant containing gastrin peptide was removed from the cell pellet. Medium and the corresponding cell content were both stored at $-20^{\circ} \mathrm{C}$ until assayed. Dilutions of the medium $(1: 100)$ and cell extract $(1: 1,000)$ were prepared for RIA and were performed by the Michigan Gastrointestinal Peptide Center using Ab 5135 specific for amidated gastrin (25). The amount of gastrin in each fraction was quantified using a standard curve prepared with iodinated gastrin or G6-gly peptide. G6-gly is a synthetic peptide of six amino acids (Tyr-Gly-Trp-Met-Asp-Phe-Gly) (26). The average amidated gastrin concentration in primary cell extracts was $5,000 \mathrm{fmol} / \mathrm{ml}$. Cell extracts from AGS cells were prepared in a similar manner. The average amount of glycine-extended progastrin (G-gly) was $241 \mathrm{fmol} / \mathrm{ml}$.
Gastrin mRNA quantification. At the end of the designated incubation times with or without agonist, total RNA was prepared using Tri Reagent (Life Technologies, Inc., Gaithersburg, MD). For Northern blot analysis, RNA was resolved on a Mops-formaldehyde $1 \%$ agarose gel and transferred to nylon membranes (Hybond-N ${ }^{+}$; Amersham Corp., Arlington Heights, IL) by capillary action. After transfer, the nylon membrane was probed overnight with a radiolabeled cDNA probe encoding glyceraldehyde phosphate dehydrogenase (GAPDH) (Rediprime kit; Amersham Corp.). After autoradiography, the membrane was reprobed with a riboprobe complementary to the third exon of the human gastrin gene in $50 \%$ formamide.

$8 \mu \mathrm{g}$ of total RNA from cell cultures was reverse transcribed using the SuperScript-RT Preamplification Kit (Life Technologies, Inc.). The cDNA obtained from this reaction was added to "HotStart 100" tubes (Molecular Bio-Products; Life Technologies, Inc.) along with PCR buffer, $\mathrm{MgCl}_{2}$, dNTPs, Taq DNA polymerase, and gene specific primers for gastrin and GAPDH added simultaneously. The reagents were denatured for $30 \mathrm{~s}$ at $95^{\circ} \mathrm{C}$, annealed for $2 \mathrm{~min}$ at $60^{\circ} \mathrm{C}$, and extension occurred at $72^{\circ} \mathrm{C}$ for 4 min over a total of 32 cycles. PCR analysis of gastrin and GAPDH RNA from G cell cultures was optimized separately to establish the optimal number of cycles for each primer pair which was 25 and 32 cycles, respectively. GAPDH primers were added first for seven cycles, then gastrin primers were added second so that both cDNAs were amplified simultaneously. The canine-specific primers were (forward) ${ }^{5}$ ATGCAGCGACTGTGTGTGTATGTAC and (reverse) ${ }^{5}$ 'TCACCTTCCTCAGCACTGCGGCGGC that produced a 302-bp product corresponding to gastrin coding exons 2 and 3 (27). Gene specific primers for the human gastrin gene were ${ }^{5}$ ATGCAGCGACTATGTGTGTGTATGT for the forward and ${ }^{5}$ TTCTCATCCTCAGCACTGCGGCGGC for the reverse primer and produced a 383 -bp product corresponding to exons 2 and 3 (28). The GAPDH-specific primers were purchased from Clontech (Palo Alto, CA). The products were analyzed on a $1.3 \%$ agarose gel adjacent to 100 -bp markers (GIBCO BRL). The PCR product was confirmed using Southern blot analysis and a riboprobe complementary to the third exon of the human gastrin gene.

Data analysis. Quantitative analysis of the ethidium bromidestained gel containing RT-PCR products was achieved using a PhosphorImager (Molecular Dynamics, Sunnyvale, CA) equipped with ImageQuant software (Molecular Dynamics). mRNA abundance was expressed as the ratio of gastrin mRNA to GAPDH determined by values of relative fluorescence.

Immunohistochemistry and indirect immunofluorescence. Dog or human antral tissue was obtained after approval from each respective animal or human Institutional Review Board. The tissue was fixed in $4 \%$ paraformaldehyde-PBS for $30 \mathrm{~min}$, dehydrated, and paraffin-embedded. 3- $\mu \mathrm{m}$ sections were prepared, deparaffinized through an alcohol series, and permeabilized in $0.3 \% \mathrm{H}_{2} \mathrm{O}_{2}$ and $100 \%$ methanol. AGS cells were cultured on slides and fixed for $30 \mathrm{~min}$ in $4 \%$ paraformaldehyde-PBS. The sections or slides were blocked in $5 \%$ normal goat serum, $1 \%$ BSA, $0.1 \%$ Triton X-100, $0.1 \%$ Tween 20 in PBS for $1 \mathrm{~h}$ before an overnight incubation with mouse anti-EGF receptor (Transduction Laboratories, Inc., Lexington, KY), rabbit antigastrin (DAKO Corp, Carpinteria, CA), or mouse anti-TGF $\alpha$ (Oncogene Sciences, Inc., Mineola, NY) antibody. The DAKO antigastrin antibody detects both processed and unprocessed forms of gastrin. A 1:200 dilution of the secondary anti-rabbit or anti-mouse IgG antibody was added for $1 \mathrm{~h}$ and visualized with avidin-biotin complexes using the Vectastain Elite ABC Kit (Vector Laboratories, Inc., Burlingame, CA). Dual histochemical labeling was achieved using the Vectastain ABC Peroxidase and Alkaline Phosphatase Labeling Kits that included a horseradish peroxidase-tagged goat antimouse antibody to detect the EGF receptor with diaminobenzidine substrate and an alkaline phosphatase-tagged goat anti-rabbit antibody to detect gastrin with the Vector red alkaline phosphatase substrate. Indirect immunofluorescence was performed using a fluorescein-tagged goat anti-rabbit antibody to detect the antigen-antibody complexes binding to gastrin and Texas red-tagged goat anti-mouse 


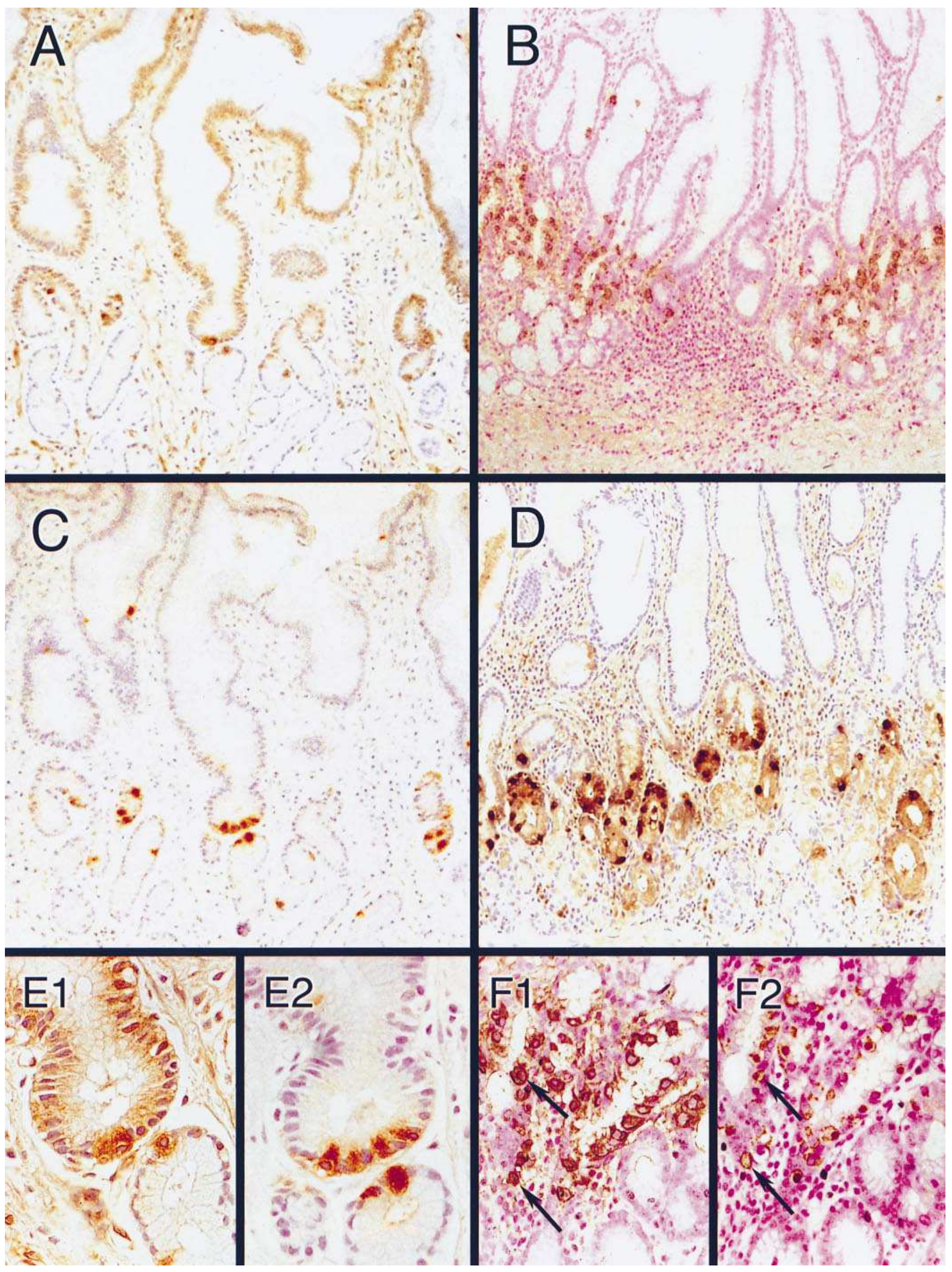

Figure 1. Immunocytochemical localization of the EGF receptor and gastrin. 3- $\mu$ m sections of canine $(A, C, E)$ or human antral tissue $(B, D, F)$ were stained with mouse EGF receptor (1:50 dilution) $(A, B, E 1, F 1)$ or rabbit gastrin (1:800 dilution) $(C, D, E 2, F 2)$ antibodies and visualized using the Vectastain Elite ABC Peroxidase Kit. $E$ and $F$ show the localization of EGF receptor ( $E 1$ and $F 1)$ and gastrin antibody ( $E 2$ and $F 2)$ staining in serial sections of dog and human antral tissues, respectively. $A-D, \times 100 ; E, \times 400$; and $F, \times 300$. 


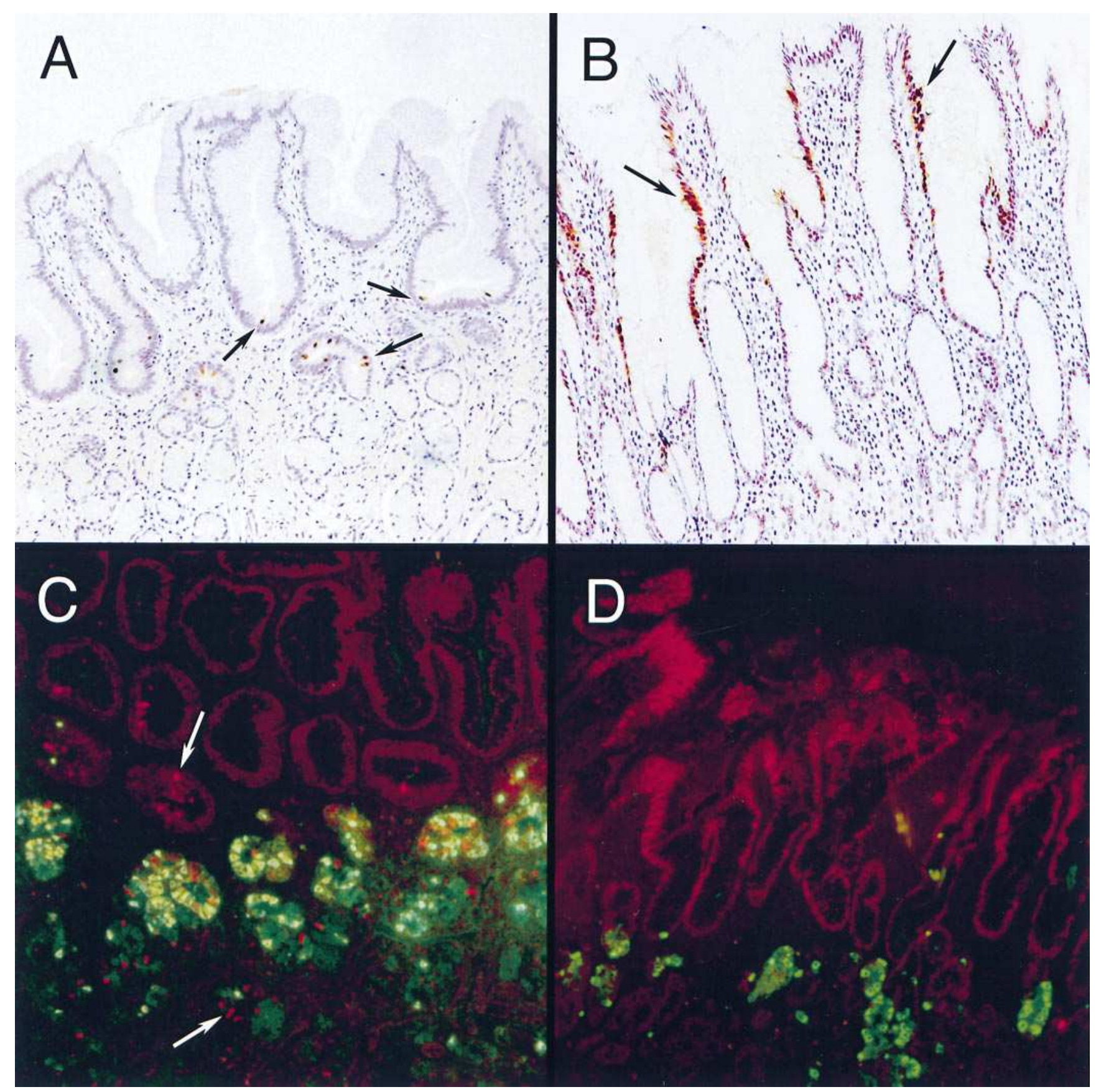

Figure 2. Immunocytochemical localization of TGF $\alpha$ and gastrin. 3- $\mu$ m sections of canine $(A$ and $C)$ and human $(B$ and $D)$ antral tissue were stained with TGF $\alpha$ (1:50 dilution) $(A)$, gastrin (1:800 dilution) $(B)$, or both $(C$ and $D)$ antibodies. The antigen-antibody complexes were visualized by immunohistochemical methods $(A$ and $B)$ or indirect immunofluorescence $(C$ and $D)$. All sections were photographed $\times 100$. Black arrows, cells staining with TGF $\alpha$ antibody. Indirect immunofluorescence patterns were as follows: TGF $\alpha$ (Texas red) and gastrin (fluorescein). White arrows, canine TGF $\alpha$ staining cells. Colocalization of TGF $\alpha$ and gastrin antibodies were indicated by the confluence of the indirect immunofluorescence signals (yellow).

antibody to detect the complexes binding to TGF $\alpha$ (Vector Laboratories, Inc.).

Electrophoretic mobility shift assays (EMSAs). Nuclear extracts were prepared by detergent lysis (29) from AGS cells cultured in serum-free media for $24 \mathrm{~h}$, then treated for 3 or $16 \mathrm{~h}$ with $10^{-8} \mathrm{M}$ EGF. Double-stranded oligonucleotide cassettes corresponding to the gERE element were end-labeled with $\left[{ }^{32} \mathrm{P}\right] \mathrm{dCTP}$ using Klenow. Radiolabeled gERE probe (GGGGCGGGGTGGGGGG; 30,000 cpm/0.1 ng) was incubated at $25^{\circ} \mathrm{C}$ with AGS nuclear extracts in a final volume of $20 \mu \mathrm{l}$ containing EMSA buffer $(10 \mathrm{mM}$ Tris- $\mathrm{HCl}, \mathrm{pH} 7.9,1 \mathrm{mM}$ $\mathrm{ZnCl}_{2}, 100 \mathrm{mM} \mathrm{KCl}, 1 \mathrm{mM} \mathrm{Na}{ }_{2}$ EDTA, $1 \mathrm{mM}$ DTT, $5 \mathrm{mM} \mathrm{MgCl}_{2}$, and $10 \%$ glycerol). Oligonucleotide competitors at 100 times the molar concentration of the probe were used to compete for specific binding. Sp1 antiserum (Santa Cruz Biotechnology, Santa Cruz, CA) was incubated with AGS extracts $15 \mathrm{~min}$ before adding the probe. DNAprotein complexes were resolved on a $4 \%$ nondenaturing polyacryl- 
amide gel containing $45 \mathrm{mM}$ Tris base $/ 45 \mathrm{mM}$ boric acid/1 mM $\mathrm{Na}_{2}$ EDTA.

\section{Results}

The EGF receptor colocalizes to the antral $G$ cell. To investigate the hypothesis that EGF receptor ligands stimulate gastrin gene expression, we studied the location of the EGF receptor by immunohistochemistry in both canine and human antral tissues. Serial sections of antrum were prepared and stained with gastrin or EGF receptor antibody. Fig. 1 demonstrates that the location of the most intense EGF receptor staining occurs in the mid-antral glands. In the dog antrum, EGF receptor staining was most intense in surface mucous cells and discrete cells of the mid-antral glands (Fig. $1 A$ ). This pattern of expression correlated with a previous study demonstrating that ${ }^{125} \mathrm{I}-\mathrm{EGF}$ binding sites are present on the mucosa of canine antrum (30). Similarly, in the human antrum, EGF receptor staining was most intense within the mid-antral glands but was undetectable on the surface mucous cells (Fig. $1 B$ ). Gastrin-expressing cells were also located in the mid-antral glands of the canine and human mucosa (Fig. 1, $C$ and $D$ ) and thus colocalized with the most intense EGF receptor antibody staining (Fig. 1, $E$ and $F$ ). Using dual labeling immunohistochemical techniques, colocalization of EGF receptor expression and gastrin in both species was confirmed (data not shown).

Since TGF $\alpha$ is expressed in normal antral mucosa, immunohistochemical techniques were used to locate the cells expressing TGF $\alpha$ (Fig. 2). In the dog, TGF $\alpha$ expression was detected at the base of the crypts and in mid-antral glands with some cells expressing both gastrin and TGF $\alpha$ (Fig. 2, $A$ and $C$ ). In the human antrum, TGFà was expressed primarily by surface mucous cells, a finding that was distinctly different from expression in the dog antrum. In addition, colocalization studies confirmed that gastrin-expressing cells in the mid-antrum do not express detectable amounts of TGF $\alpha$ (Fig. $2 D$ ).

$E G F / T G F \alpha$ stimulate an increase in gastrin $m R N A$ levels in canine $G$ cells. Since the antral G cell clearly possesses EGF receptors and is capable presumably of responding directly to EGF or TGF $\alpha$, we studied gastrin gene expression in gastrinexpressing cell cultures. After incubating the $\mathrm{G}$ cell cultures with either $10^{-8} \mathrm{M}$ EGF or $10^{-7} \mathrm{M}$ bombesin for $16 \mathrm{~h}$, total cell RNA was prepared for Northern blot analysis (Fig. 3). A $20 \%$ increase in gastrin mRNA level was observed in response to EGF compared to GAPDH (Fig. 3). Densitometric analysis revealed no significant change in gastrin mRNA in response to bombesin.

To further evaluate the time course of gastrin mRNA induction and to study the effect of TGF $\alpha$ on gastrin mRNA, duplicate plates of primary $G$ cells were prepared and treated with $10^{-8} \mathrm{M}$ TGF $\alpha$. Because of limitations in obtaining large quantities of canine $\mathrm{G}$ cells sufficient to routinely prepare total RNA for Northern blots, analysis of multiple samples was performed using RT-PCR. RT-PCR primer pairs complementary to canine exons 2 and 3 were based upon the published cDNA sequence (27). The expected dog gastrin product was $302 \mathrm{bp}$. Human GAPDH primers were used simultaneously in the reaction mixture to document the integrity of the RNA and to control for the amount of cDNA used in each reaction. Changes in gastrin mRNA were expressed as a function of GAPDH mRNA levels. A representative ethidium bromidestained gel is shown in Fig. $4 A$. The results from three inde-
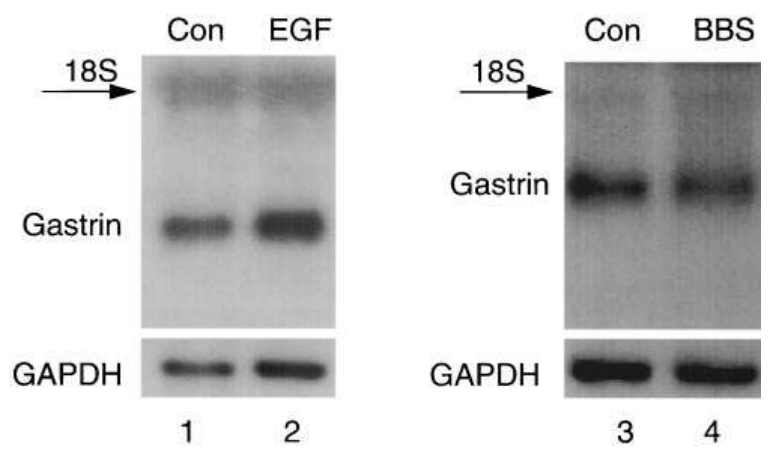

Figure 3. Northern blot analysis of gastrin gene expression regulation by EGF or bombesin in primary canine cell cultures. Northern blot of total RNA extracted from primary dog cells treated with $10^{-8} \mathrm{M}$ EGF or $10^{-7} \mathrm{M}$ bombesin $(B B S)$ for $16 \mathrm{~h}$. Primary cultures were prepared from canine antrum and enriched for gastrin-expressing cells using counterflow elutriation. The cells were plated on Matrigel for $16 \mathrm{~h}$ before replacing with MEM without serum for $24 \mathrm{~h}$. An entire dog preparation was used for each treatment. Total RNA was extracted and resolved on a $1 \%$ Mops-formaldehyde gel for Northern blot analysis with a cDNA probe to GAPDH. The blot was then reprobed with a riboprobe complementary to the third exon of the human gastrin promoter in $50 \%$ formamide.

pendent experiments are plotted as a function of time and show that $10^{-8} \mathrm{M}$ TGF $\alpha$ stimulated a 2.5 -fold increase in gastrin relative to GAPDH mRNA by $16 \mathrm{~h}$ (Fig. $4 \mathrm{~B}$ ). The magnitude and time course of activation was similar to what was reported previously for induction of the human gastrin gene in stable transformants of $\mathrm{GH}_{4}$ cells (20). Moreover, these results are consistent with the observation that the mouse and rat promoters are also stimulated by EGF (31; our unpublished observations). Therefore, activation of the EGF receptor by either EGF or TGF $\alpha$ stimulates gastrin gene expression in the native antral $\mathrm{G}$ cell.

EGF/TGF $\alpha$ stimulate gastrin release in canine $G$ cells. The observation that EGF/TGF $\alpha$ stimulated gastrin gene expression raised the possibility that these ligands might also stimulate gastrin release. To study the effect of EGF, TGF $\alpha$, and bombesin on gastrin release, the medium was collected after treating the cells for $2 \mathrm{~h}$ with agonists. A dose-response analysis of these ligands demonstrated that the maximal effective dose for gastrin release was $10^{-8} \mathrm{M}$ for the EGF receptor ligands (data not shown). Nanomolar concentrations of bombesin are sufficient to stimulate gastrin secretion from primary canine cultures by at least $200 \%$ above control levels within $2 \mathrm{~h}$ (2). Using the same maximal secretagogue concentrations for each agonist, bombesin stimulated gastrin release (as a percentage of cell content) $250 \%( \pm 49 \%$ ) above control levels; whereas EGF and TGF $\alpha$ both stimulated gastrin release only $50 \%$ ( \pm 10 and $26 \%$, respectively) above controls in four experiments. The $P$ values for EGF, TGF $\alpha$, and bombesin were $0.05,0.11,0.02$, respectively, indicating low but significant release induced by EGF receptor activation. Similarly, a modest but significant increase in plasma gastrin levels was observed in fasting pigs receiving EGF (8). Therefore, bombesin was the more potent regulator of gastrin release; whereas activation of the EGF receptor was a more effective activator of gastrin gene expression. 

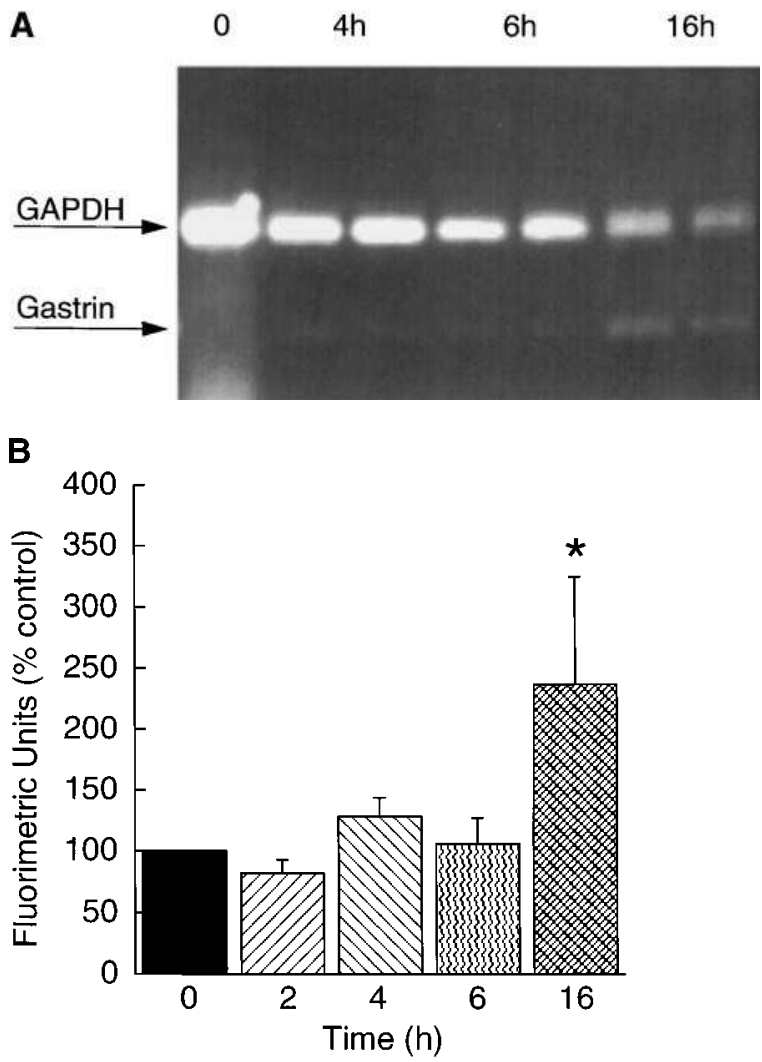

Figure 4. TGF $\alpha$ induction of gastrin gene expression over time in canine primary cultures. Primary canine cultures were treated with $10^{-8} \mathrm{M}$ TGF $\alpha$ for the times designated before the preparation of total RNA. $8-\mu \mathrm{g}$ of total RNA was reverse transcribed and $4 \mu \mathrm{g}$ of the cDNA was amplified simultaneously with GAPDH and canine gastrin primers. The PCR products were resolved on a $1.3 \%$ agaroseethidium bromide gel $(A)$. A total of at least four experiments were quantified on a fluoroimager and expressed as a percentage of the control gastrin/GAPDH ratio $(B)$. The means \pm SEM are shown. $* P<0.08$.
EGF/TGF $\alpha$ stimulate an increase in gastrin $m R N A$ levels and promoter activity in human gastric cell lines. To study gastrin gene expression in human cell lines, changes in gastrin mRNA levels in the AGS cell line were quantified using RTPCR (Fig. 5). AGS cells express small amounts of gastrin mRNA; therefore, to assess whether TGF $\alpha$ increases gastrin mRNA levels, the cells were cultured for $24 \mathrm{~h}$ in serum-free media. Total RNA was prepared after the cells were treated with $10^{-8} \mathrm{M}$ TGF $\alpha$ for the times indicated. Total RNA was used for RT-PCR using human gastrin and GAPDH primers simultaneously. The products were then resolved on an ethidium bromide stained gel (Fig. $5 A$ ). The results were quantified by fluorimetry and demonstrated that TGF $\alpha$ stimulates a fourfold increase in gastrin mRNA levels relative to GAPDH mRNA and that maximal induction occurred between 2 and $4 \mathrm{~h}$ after TGF $\alpha$ treatment (Fig. 5 B). A similar time course and magnitude of induction was observed for AGS cells stimulated with $10^{-8} \mathrm{M}$ EGF (data not shown). The MKN-45 cell line that is also derived from a human gastric adenocarcinoma has been shown previously to express the EGF receptor and gastrin peptide $(32,33)$. We found that TGF $\alpha$ treatment of the MKN45 cell line also stimulated a fourfold increase in gastrin mRNA levels (data not shown). Thus, consistent with the presence of EGF receptors on the surface of human G cells, an increase in gastrin mRNA levels was induced by TGF $\alpha$ in human cell lines.

To determine whether AGS cells express gastrin peptide, paraformaldehyde-fixed AGS cells were immunostained with a commercial gastrin antibody or antibody raised against the progastrin glycine-extended form (26). The results shown in Fig. 6 demonstrate that both a gastrin antibody recognizing processed and unprocessed forms of gastrin and antibody recognizing glycine-extended forms stained AGS cells. Although the G6-gly $\mathrm{Ab}$ (Fig. 6, $C$ and $D$ ) also recognizes cholecystokinin (26), glycine-extended gastrin peptide competed for $\mathrm{Ab}$ staining demonstrating the specificity for G-gly in this cell. Moreover, gastrin was not detected in an RIA using the gastrin antibody 5135 that specifically recognizes amidated gastrin
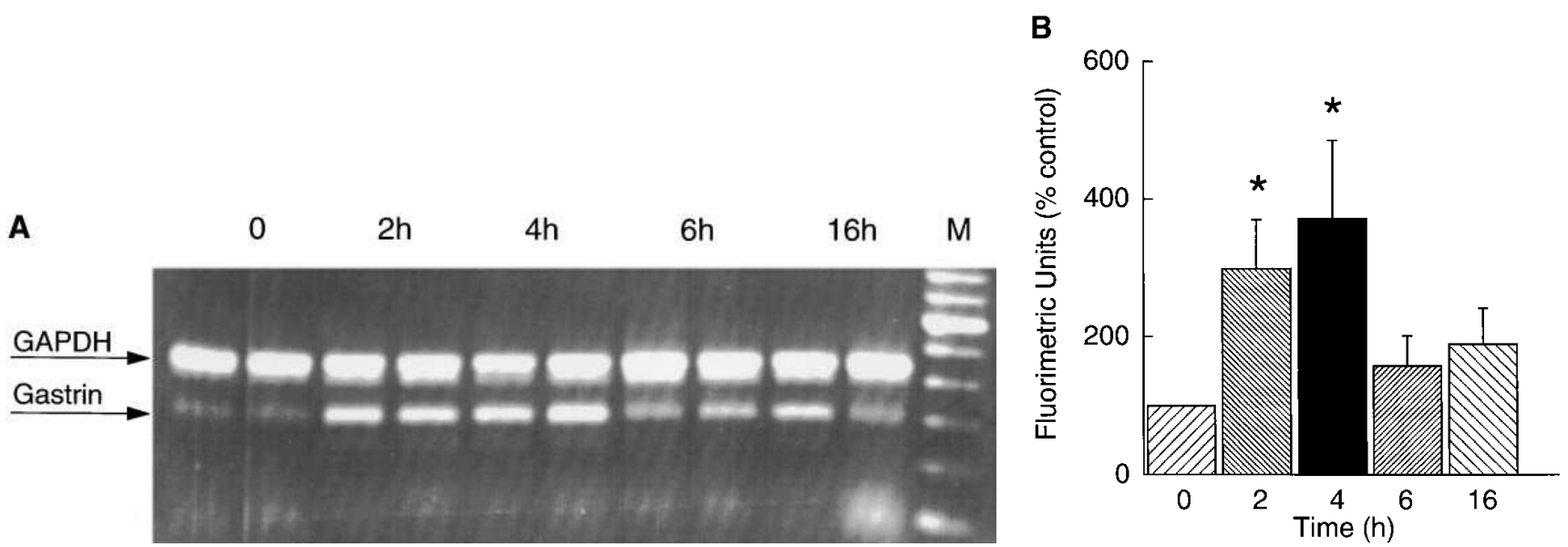

Figure 5. Regulation of endogenous gastrin gene expression in a gastric adenocarcinoma cell line. The AGS gastric adenocarcinoma cell line was cultured in serum-free media for $24 \mathrm{~h}$, then treated with $10^{-8} \mathrm{M}$ TGF $\alpha$ for the times designated before the preparation of total RNA. RT-PCR was performed on $8 \mu \mathrm{g}$ of total RNA with GAPDH and human gastrin primers used simultaneously in the reaction mixture as described in Fig. 4. The PCR products were resolved on a $1.3 \%$ agarose-ethidium bromide gel $(A)$. The results were quantified on a fluoroimager. The fluorimetric units shown represent the ratio of gastrin to GAPDH expressed as a percentage of the untreated control gastrin/GAPDH ratio $(B)$. The means \pm SEM for three experiments are shown. $* P<0.05$. 


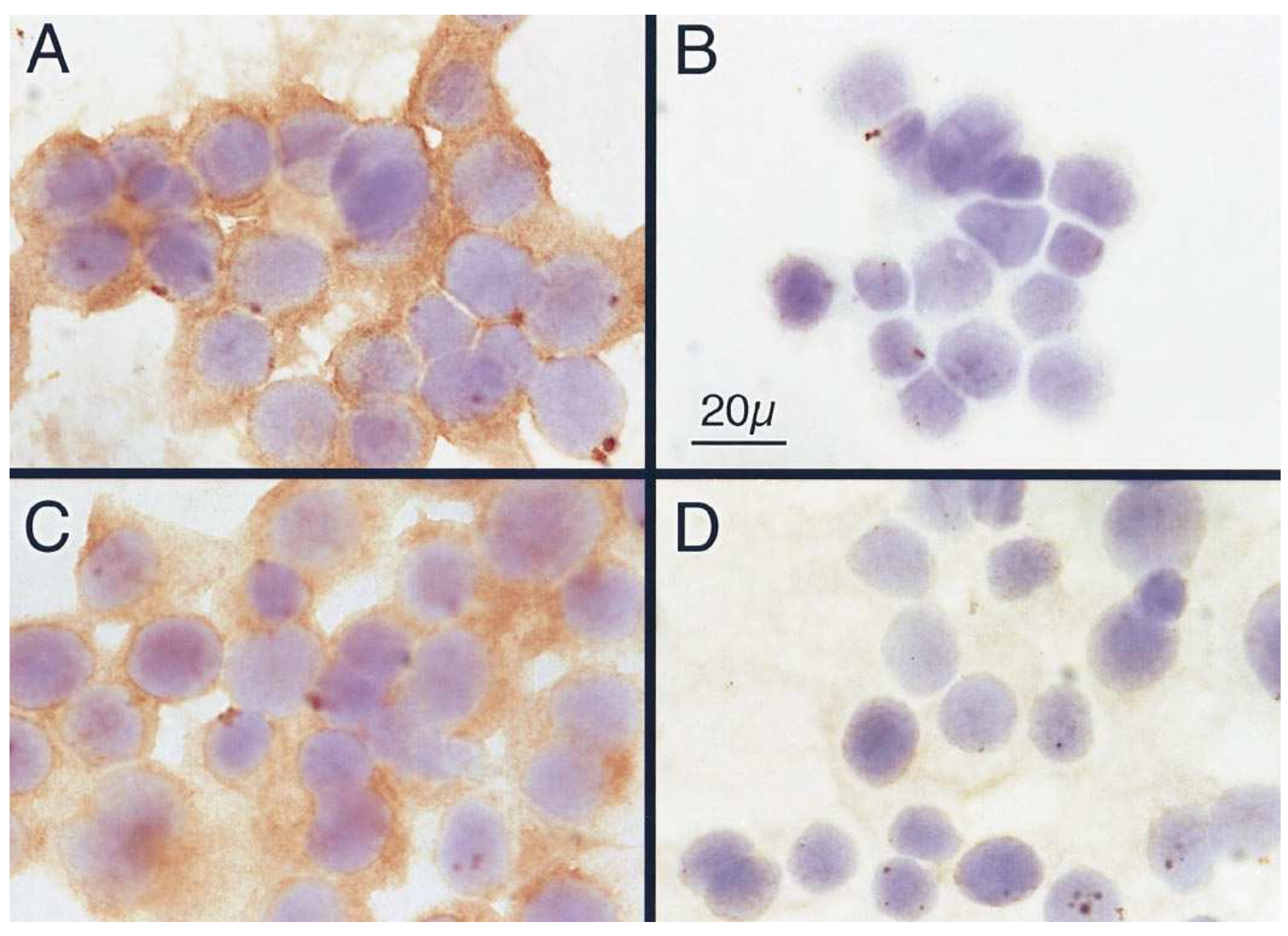

Figure 6. Immunodetection of gastrin peptides in AGS cells. AGS cells were cultured on glass slides then fixed in 4\% paraformaldehyde-PBS. The permeabilized cells were then incubated with $(A)$ anti-human gastrin antibody (1:100 dilution) or $(C)$ anti-G6-gly antisera (1:200 dilution) and visualized using the Vectastain Elite ABC peroxidase kit. To demonstrate Ab specificity, the cells were incubated with $(B)$ antigastrin antibody and $10 \mu \mathrm{M}$ gastrin peptide, or $(D)$ anti-G6-gly Ab and $10 \mu \mathrm{M}$ G-gly peptide. $\times 1,000$.

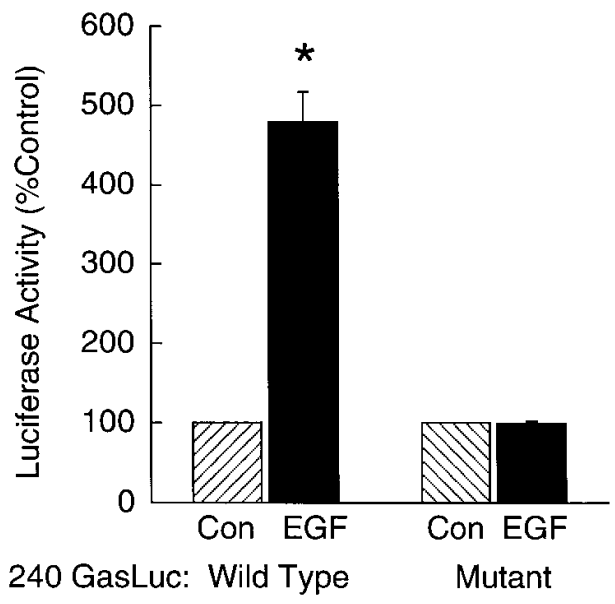

Figure 7. Regulation of gastrin reporter constructs stably expressed in the AGS cell line. The wild-type or mutant 240 GasLuc reporter constructs were cotransfected into AGS cells with a pCMV neomycin plasmid using calcium phosphate coprecipitation. Stable transformants were selected in G418 and pooled. The pooled transformants were placed in serum-free media for $24 \mathrm{~h}$ and then stimulated with
(25) $(<1 \mathrm{fmol} / \mathrm{ml})$. However, $241 \mathrm{fmol} / \mathrm{ml}$ of progastrin was detected by RIA using the antibody specific for glycine-extended gastrin (G6-gly Ab).

To determine whether EGF/TGF $\alpha$ induction of the human gastrin gene maps to the gERE element, the 240 GasLuc construct containing $240 \mathrm{bp}$ of $5^{\prime}$ flanking sequence and the first exon was stably transfected into the AGS cells (Fig. 7). The induction observed with the wild-type construct was compared to the activity of a 240 GasLuc construct containing a mutation within the gERE element. A time course of induction with EGF demonstrated that maximal promoter activity was achieved

$10^{-8} \mathrm{M}$ EGF. Cell lysates were prepared $3 \mathrm{~h}$ after EGF treatment. The results are expressed as a percentage of the luciferase activity from untreated cells $(C o n)$. The means \pm SEM for three experiments performed in triplicate are shown. $* P<0.001$. The 240 GasLuc reporter construct contains the first $240 \mathrm{bp}$ of the human gastrin promoter and the first exon subcloned into a luciferase expression vector (light unit activity of controls $=\sim 1,500$ ). The mutant 240 GasLuc construct contains a mutation within the gERE element (light unit activity of untreated mutant controls $=30$ ). 


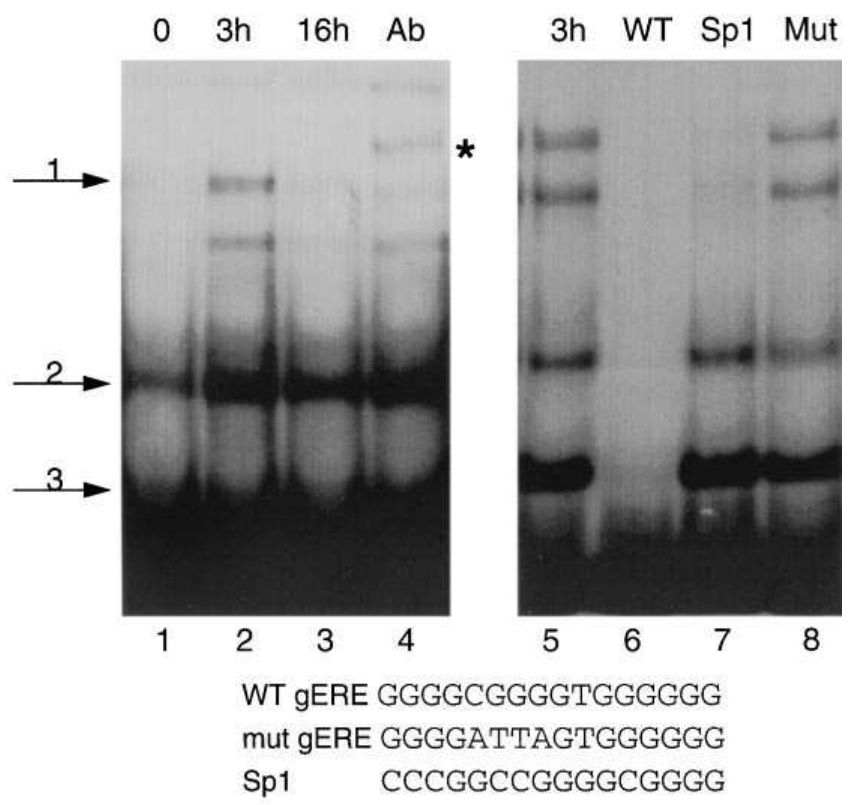

Figure 8. EGF induces binding of nuclear protein from AGS cells to the gERE element. AGS cells cultured for $24 \mathrm{~h}$ in serum-free media were treated with $10^{-8} \mathrm{M}$ EGF for 3 and $16 \mathrm{~h}$ before the preparation of nuclear extracts by detergent lysis. The gERE element was used as a probe to detect inducible binding of nuclear protein. Lane 1, extracts from untreated cells; lane 2, extracts from cells treated for $3 \mathrm{~h}$; lane 3 , extracts from cells treated for $16 \mathrm{~h}$; lane 4, extracts from cells treated for $3 \mathrm{~h}$ plus Sp1 antibody; lane 5, 3-h treated extracts; lane 6, competed with $\times 100$ of WT gERE; lane 7 , competed with $\times 100$ of Sp1; lane 8 competed with $\times 100$ of mutant gERE. Arrows, complex 1,2 , and 3 described in the text. *Supershifted Sp1 protein.

within $3 \mathrm{~h}$, paralleling induction of the endogenous gastrin gene in AGS cells (data not shown). The 240 GasLuc construct was induced nearly fivefold by $10^{-8} \mathrm{M}$ EGF; however, a mutation only in the gERE element (mutant 240 GasLuc) eliminated both basal promoter activity and induction by EGF. The same fold induction was observed with TGF $\alpha$ (our unpublished observations). The fold induction by EGF was similar to that observed previously in stable transformants of $\mathrm{GH}_{4}$ cells expressing the human gastrin gene and transient transformants expressing the 240 GasLuc construct $(20,34)$.

EGF induction of the transfected gastrin promoter correlates with inducible binding to gERE. To demonstrate that the complexes binding to the gERE element were similar to those described previously (35), EMSAs were performed using the gERE element as a probe and AGS nuclear extracts from EGF-stimulated cells (Fig. 8). Three major complexes from AGS nuclear extracts were observed to bind the gERE element. Complex 1 contains both Sp1 and a second zinc finger factor called ZBP-89 (34). Complexes 2 and 3 have been designated as gERP 1 and 2; however, the proteins comprising these complexes have not been identified (35). The results indicate that the slowest migrating complex (complex 1) was induced by EGF within $3 \mathrm{~h}$. The increase was primarily a result of an increase in Sp1 binding since Sp1 antibodies supershifted most of complex 1 . Induction of the complex returned to near baseline by $16 \mathrm{~h}$. To demonstrate that the 4-bp gERE mutation eliminated the binding of all three complexes, competition with the mutant element was performed. The results showed that the mutant gERE did not compete for the binding of complexes 1, 2, or 3; whereas, Sp1 competed for complex 1 and WT gERE competed for all three complexes. Thus, the loss of EGF induction observed with a mutated gERE (Fig. 7) was because of the loss of binding of these three complexes.

\section{Discussion}

The specific extracellular regulators of gastrin release are well documented; however, the mediators of gastrin synthesis have not been well-defined. Based upon preliminary studies in animals and cell lines, we tested the hypothesis that activation of the EGF receptor by either EGF or TGF $\alpha$ stimulates gastrin gene expression. The studies reported here demonstrate that the EGF receptor colocalizes to the antral $G$ cell and that treatment of antral $\mathrm{G}$ cell cultures with EGF receptor ligands will stimulate gastrin gene expression. Moreover, the gERE element mediates this induction to the human gastrin gene in human gastric cell lines. Thus activation of the EGF receptor is a physiologic regulator of gastrin synthesis. Furthermore, these results are consistent with prior in vivo and in vitro studies in both animals and transfected cell lines showing that the mouse, pig, and human gastrin genes are responsive to EGF $(7,8,19,31)$.

$\mathrm{EGF} / \mathrm{TGF} \alpha$ regulation of the gastrin gene is not surprising when viewed in the context of the widespread expression of EGF receptor ligands by the gastric mucosa (11). Both EGF and TGF $\alpha$ exhibited the same effect on gastrin release and gene expression consistent with prior evidence that both ligands are equipotent in the stomach (16). Colocalization of the EGF receptor to $G$ cells was observed in both the human and canine antrum; however, the number of $\mathrm{G}$ cells possessing EGF receptors appeared greater in the human antrum. Thus, there may be species differences in the number and types of cells expressing the EGF receptor. The species differences were most impressive when comparing the distribution of $\mathrm{TGF} \alpha$ peptide expression. In the human antrum, the most intense staining with TGF $\alpha$ antibody was in surface mucous epithelial cells but was undetectable in the mid-antral glands. In contrast, the most intense TGF $\alpha$ staining in the canine antrum occurred in discrete cells of the mid-glandular region and less so in the mucous cell layer with a number of cells expressing both TGF $\alpha$ and gastrin. Interestingly, EGF receptor antibody staining was quite prevalent in surface mucous cells of the dog but undetectable in the same cells in the human antrum. The distribution of TGF $\alpha$ in human antrum was similar to what has been reported previously (13). The significance of these findings is not understood, but may help to explain the epithelial cell layers that undergo hypertrophy in certain disease states. For example, in Ménétrier's disease, the surface mucous cell layer in the body of the stomach undergoes hypertrophy and hyperplasia, presumably because of the influence of excess TGF $\alpha$ production (13). However, the antrum is usually spared (36), perhaps because of the significantly fewer EGF receptors on these cells. The species differences in the distribution of EGF receptor ligands may also provide some insight into why there are differences in the promoter elements in the nonhuman gastrin genes (37). In particular, the mouse and rat genes are missing the gERE element, yet remain EGF responsive, albeit not to the same extent as the human promoter (31; our unpublished observations).

As reported for $\mathrm{GH}_{4}$ transformants (19), bombesin or GRP 
treatment of native $\mathrm{G}$ cell cultures had little effect on gastrin gene expression despite its ability to stimulate gastrin release. Since the primary cultures were not comprised exclusively of $\mathrm{G}$ cells, there was the possibility that another cell type was initially activated by EGF/TGF $\alpha$ and released a second mediator. However, this result is unlikely since $\mathrm{G}$ cells appear to possess a higher concentration of EGF receptors compared to the surrounding epithelial cells. Moreover, EGF and TGF $\alpha$ were found to also regulate gastrin gene expression in a human gastric cell line. In particular, RT-PCR of total RNA from AGS cells revealed a fourfold increase in gastrin mRNA levels in response to TGF $\alpha$. Therefore, activation of the EGF receptor in a homogenous cell population also stimulated gastrin gene expression, indicating that the response to receptor activation is probably direct. In contrast to bombesin, the EGF receptor ligands were weak secretagogues. The AGS cells did not express mature gastrin and thus were not used to study gastrin secretion. Collectively the data indicate that gastrin secretion and gene expression are regulated by different extracellular mediators and signal transduction pathways.

This result is consistent with what is known about peptide synthesis and release in other systems and can be explained by considering that there are multiple regulators, e.g., bombesin and $\mathrm{EGF} / \mathrm{TGF} \alpha$, that may act coordinately to respond to different environmental cues at different times. Although EGF/ TGF $\alpha$ in the absence of bombesin may stimulate a small amount of gastrin release, the amount released in vivo will likely reflect the effects of the more potent secretagogue, i.e., bombesin or GRP. Alternatively, extracellular signals may be used to elicit different types of responses over time. Bombesin may mediate the release of gastrin acutely, while EGF receptor ligands may mediate the release of low levels of gastrin chronically over time.

Differential regulation of peptide synthesis and release by $\mathrm{EGF} / \mathrm{TGF} \alpha$ has been documented in other endocrine systems (10). However, examples of EGF as a secretagogue are less frequent than descriptions of its role as a regulator of cellular proliferation and differentiation. EGF stimulates release of pituitary ACTH and subsequent adrenal cortical secretion with similar potency to corticotropin-releasing factor (CRF) in fetal lambs (38). It also will stimulate prolactin synthesis (gene transcription) but minimal prolactin release from rat pituitary cell lines $(39,40)$. EGF stimulates the release of growth hormone and luteinizing hormone (41-43). However, growth hormone gene expression is inhibited by EGF. In the pancreas, EGF stimulates acinar cell growth as measured by $\left[{ }^{3} \mathrm{H}\right]$ thymidine incorporation into DNA and thus is primarily a mitogen in this organ system (44). Similarly, EGF functions as a mitogen on mammary and epithelial cells (45).

Extracellular mediators that regulate amylase synthesis and not release have been studied in the exocrine pancreas. Insulin and dexamethasone both individually stimulate amylase synthesis, but not its release $(46,47)$. Insulin increases DNA synthesis in pancreatic acinar cells within the first $24 \mathrm{~h}$ and selectively increases amylase content compared to total cellular protein within $48 \mathrm{~h}$ (48). Similarly, glucocorticoids will also increase amylase content by stimulating amylase gene transcription in addition to cellular differentiation, a process that is delayed for at least $12 \mathrm{~h}$ and then reaches a maximum within $48 \mathrm{~h}$ (46). Although cholecystokinin (CCK) will also stimulate amylase synthesis, it, along with acetylcholine, is a major regulator of amylase release $(44,49)$. Taken together, proliferation, dif- ferentiation, and secretion of amylase from the pancreatic acinar cell are the result of at least three hormones that exert overlapping, but distinctive functions. Interestingly, both insulin and dexamethasone increase amylase content after a lag period of several hours to days, but do not stimulate significant release in the absence of $\mathrm{CCK}$, an event that occurs within minutes.

We have studied previously gastrin gene expression in transfected $\mathrm{GH}_{4}$ cells and showed that EGF induction maps to a GC-rich element within the human gastrin promoter (20). We now show that this same element confers EGF/TGF $\alpha$ induction in a gastrin-expressing human cell line. As predicted from our prior studies (35), Sp1 bound to the gERE element in response to EGF receptor activation. Thus, inducible transactivation of the gastrin promoter is mediated in part by Sp1. It remains to be determined what role the other complexes play and whether inducible binding of these factors is a result of phosphorylation status.

In summary, the results reported here establish EGF receptor activation as a major regulator of gastrin gene expression and demonstrate that gastrin secretion and synthesis are differentially regulated. These studies also establish the AGS cell line as a relevant system to study regulation of the human gastrin gene. Furthermore, these studies confirm that transcription factor $\mathrm{Sp} 1$ is the most likely target of the EGF receptor signaling cascade that in turn binds to and transactivates the gastrin promoter.

\section{Acknowledgments}

The authors wish to acknowledge the technical assistance of Pia Sullivan for preparing $\mathrm{G}$ cell cultures, Lara Post for assistance with gastrin release studies, Mark Hoeltzel for preparing the radioimmunoassays, Judy Poore for immunohistochemical preparations, and the assistance of Gail Kelsey in preparing the manuscript. Oligonucleotides were synthesized by the University of Michigan DNA synthesis core facility.

This work was supported by Public Health Service grants DK45729 to J.L. Merchant and DK-34306 to J. Del Valle. J.L. Merchant is an investigator of the Howard Hughes Medical Institute. These studies were also supported in part by Public Health Service grants to the General Clinical Research Center (M01-RR-00042) and to the University of Michigan Gastrointestinal Peptide Center (DK-34533).

\section{References}

1. Giraud, A.S., A.H. Soll, F. Cuttitta, and J.H. Walsh. 1987. Bombesin stimulation of gastrin release from canine gastrin cells in primary culture. Am. J. Physiol. 252:G413-G420.

2. DelValle, J., and T. Yamada. 1990. Amino acids and amines stimulate gastrin release from canine antral G-cells via different pathways. J. Clin. Invest. 85:139-143.

3. Sugano, K., J. Park, A.H. Soll, and T. Yamada. 1987. Stimulation of gastrin release by bombesin and canine gastrin-releasing peptides. J. Clin. Invest. 79:935-942.

4. Campos, R.V., A.M.J. Buchan, R.M. Meloche, R.A. Pederson, Y.N. Kwok, and D.H. Coy. 1990. Gastrin secretion from human antral G cells in culture. Gastroenterology. 99:36-44.

5. Brand, S.J., and D. Stone. 1988. Reciprocal regulation of antral gastrin and somatostatin gene expression by omeprazole-induced achlorhydria. J. Clin. Invest. 82:1059-1066.

6. Wu, S.V., A. Giraud, M. Mogard, K. Sumii, and J.H. Walsh. 1990. Effects of inhibition of gastric secretion on antral gastrin and somatostatin gene expression in rats. Am. J. Physiol. 258:G788-G793.

7. Vinter-Jensen, L., C. Orloff, J.F. Rehfeld, P.S. Seier, E.Z. Dajani, and E. Nexo. 1995. Chronic systemic treatment with epidermal growth factor induces hypergastrinaemia in Goettingen minipigs. Scand. J. Gastroenterol. 30:422-427.

8. Goodlad, R.A., M.A. Ghatei, J. Domin, S.R. Bloom, H. Gregory, and 
N.A. Wright. 1989. Plasma enteroglucagon, peptide YY and gastrin in rats deprived of luminal nutrition, and after urogastrone-EGF administration. A proliferative role for PYY in the intestinal epithelium? Experientia (Basel). 45:168169.

9. Shing, Y., G. Christofori, D. Hanahan, Y. Ono, R. Sasada, K. Igarashi, and J. Folkman. 1993. Betacellulin: a mitogen from pancreatic beta cell tumors. Science (Wash. DC). 259:1604-1606.

10. Fisher, D.A., and J. Lakshmanan. 1990. Metabolism and effects of epidermal growth factor and related growth factors in mammals. Endocr. Rev. 11: $1-25$.

11. Beauchamp, R.D., J.A. Barnard, C.M. McCutchen, J.A. Cherner, and R.J. Coffey, Jr. 1989. Localization of transforming growth factor $\alpha$ and its receptor in gastric mucosal cells. J. Clin. Invest. 84:1017-1023.

12. Murayama, Y., J.-I. Miyagawa, S. Higashiyama, S. Kondo, M. Yabu, K. Isozaki, Y. Kayanoki, S. Kanayama, Y. Shinomura, N. Taniguchi, and Y. Matsuzawa. 1995. Localization of heparin-binding epidermal growth factor-like growth factor in human gastric mucosa. Gastroenterology. 109:1051-1059.

13. Dempsey, P.J., J.R. Goldenring, C.J. Soroka, I.M. Modlin, R.W. McClure, C.D. Lind, D.A. Ahlquist, M.R. Pittelkow, D.C. Lee, E.P. Sandgren, et al. 1992. Possible role of transforming growth factor alpha in the pathogenesis of Ménétrier's disease: supportive evidence from humans and transgenic mice. Gastroenterology. 103:1950-1963.

14. Heitz, P.U., M. Kasper, S. VanNoorden, J.M. Polak, H. Gregory, and A.G.E. Pearse. 1978. Immunohistochemical localisation of urogastrone to human duodenal and submandibular glands. Gut. 19:408-413.

15. Wright, N.A., C. Pike, and G. Elia. 1990. Induction of a novel epidermal growth factor-secreting cell lineage by mucosal ulceration in human gastrointestinal stem cells. Nature (Lond.). 343:82-85.

16. Wang, L., M.R. Lucey, A.M. Fras, E.J. Wilson, and J. Del Valle. 1993. Epidermal growth factor and transforming growth factor-alpha directly inhibit parietal cell function through a similar mechanism. J. Pharmacol. Exp. Ther. 265:308-313

17. Massague, J. 1983. Epidermal growth factor-like transforming growth factor. II. Interaction with epidermal growth factor receptors in human placenta membranes and A431 cells. J. Biol. Chem. 258:13614-13620.

18. Kaise, M., A. Muraoka, J. Yamada, and T. Yamada. 1995. Epidermal growth factor induces $\mathrm{H}+, \mathrm{K}+$-ATPase $\alpha$-subunit gene expression through an element homologous to the $3^{\prime}$ half-site of the $c$-fos serum response element. $J$. Biol. Chem. 270:18637-18642.

19. Godley-Merchant, J., and S.J. Brand. 1989. Regulation of the gastrin promoter by epidermal growth factor and neuropeptides. Proc. Natl. Acad. Sci. USA. 86:3036-3040.

20. Merchant, J.L., B. Demediuk, and S.J. Brand. 1991. A GC-rich element confers epidermal growth factor responsiveness to transcription from the gastrin promoter. Mol. Cell. Biol. 11:2686-2696.

21. Barranco, S.C., C.M. Townsend, Jr., C. Casartelli, B.G. Macik, N.L. Burger, W.R. Boerwinkle, and W.K. Gourley. 1983. Establishment and characterization of an in vitro model system for human adenocarcinoma of the stomach. Cancer Res. 43:1703-1709.

22. Tahara, E., H. Ito, K. Nakagami, F. Shimamoto, M. Yamamoto, and K. Sumii. 1982. Scirrhous argyrophil cell carcinoma of the stomach with multiple production of polypeptide hormones, amine, CEA, lysozyme, and HCG. Cancer. 49:1904-1915.

23. Deng, W.P., and J.A. Nickoloff. 1992. Site-directed mutagenesis of virtually any plasmid by eliminating a unique site. Anal. Biochem. 200:81-88.

24. Shiotani, A., and J.L. Merchant. 1995. cAMP regulates gastrin gene expression. Am. J. Physiol. 269:G458-G464.

25. Rosenquist, G.L., and J.H. Walsh. 1980. Radioimmunoassay of gastrin. In Gastrointestinal Hormones. G.B. Jerzy-Glass, editor. Raven Press Ltd., New York. 769-795.

26. Marshak, D.W., L.B. Aldrich, J. DelValle, and T. Yamada. 1990. Localization of immunoreactive cholecystokinin precursor to amacrine cells and bipolar cells of the macaque monkey retina. J. Neurosci. 10:3045-3055.

27. Gantz, I., T. Takeuchi, and T. Yamada. 1990. Cloning of canine gastrin cDNA's encoding variant amino acid sequences. Digestion. 46:99-104.

28. Howell, G.M., B.L. Ziober, L.E. Humphrey, J.K. Willson, L. Sun, M.
Lynch, and M.G. Brattain. 1995. Regulation of autocrine gastrin expression by the TGF alpha autocrine loop. J. Cell. Physiol. 162:256-265.

29. Schreiber, E., P. Matthias, M.M. Muller, and W. Schaffner. 1989. Rapid detection of octamer binding proteins with 'mini-extracts,' prepared from a small number of cells. Nucleic Acids Res. 17:6419.

30. Zimmerman, R.P., T.S. Gates, C.G. Boehmer, and C.G. Mantyh. 1988 Epidermal growth factor receptors in the canine antrum. Peptides (Tarryt). 9: 1411-1414.

31. Koh, T.J., and T.C. Wang. 1995. Molecular cloning and sequencing of the murine gastrin gene. Biochem. Biophys. Res. Commun. 216:34-41.

32. Watson, S.A., L.G. Durrant, P.M. Wencyk, A.L. Watson, and D.L. Morris. 1991. Intracellular gastrin in human gastrointestinal tumor cells. J. Natl. Cancer Inst. 83:866-871.

33. Yoshida, K., E. Kyo, T. Tsujino, T. Sano, M. Niimoto, and E. Tahara 1990. Expression of epidermal growth factor, transforming growth factor-alpha and their receptor genes in human gastric carcinomas; implication for autocrine growth. Jpn. J. Cancer Res. 81:43-51.

34. Merchant, J.L., G.R. Iyer, B.R. Taylor, J.R. Kitchen, E.R. Mortensen, Z. Wang, R.J. Flintoft, J. Michel, and R. Bassel-Duby. 1996. ZBP-89, a Krüppel-type zinc finger protein, inhibits EGF induction of the gastrin promoter. Mol. Cell. Biol. 16:6644-6653.

35. Merchant, J.L., A. Shiotani, E. Mortensen, D. Shumaker, and D. Abraczinskas. 1995. EGF stimulation of the human gastrin promoter requires Sp1.J. Biol. Chem. 270:6314-6319.

36. Searcy, R.M., and J.-R. Malagelada. 1984. Ménétriér's disease and idiopathic hypertrophic gastropathy. Ann. Intern. Med. 100:565-570.

37. Bundgaard, J.R., T.O. Hansen, L. Friis-Hansen, I.J. Rourke, W.W. van Solinge, F.C. Nielsen, and J.F. Rehfeld. 1995. A distal Sp1-element is necessary for maximal activity of the human gastrin gene promoter. FEBS Lett. 369:225228

38. Polk, D.H., M.G. Ervin, J.F. Padbury, R.W. Lam, A.L. Reviczky, and D.A. Fisher. 1987. Epidermal growth factor acts as a corticotropin-releasing factor in chronically catheterized fetal lambs. J. Clin. Invest. 79:984-988.

39. Schonbrunn, A., M. Krasnoff, J.M. Westendorf, and A.H. Tashjian, Jr. 1980. Epidermal growth factor and thyrotropin-releasing hormone act similarly on a clonal pituitary cell strain. J. Cell. Biochem. 85:786-797.

40. Yajima, Y., and T. Saito. 1984. The effects of epidermal growth factor on cell proliferation and prolactin production by GH3 rat pituitary cells. J. Cell. Physiol. 120:249-256.

41. Johnson, L.K., J.D. Baxter, I. Vlodavsky, and D. Gospodarowicz. 1980. Epidermal growth factor and expression of specific genes: effects on cultured rat pituitary cells are dissociable from the mitogenic response. Proc. Natl. Acad. Sci. USA. 77:394-398.

42. Przylipiak, A., L. Kiesel, T. Rabe, K. Helm, M. Przylipiak, and B. Runnebaum. 1988. Epidermal growth factor stimulates luteinizing hormone and arachidonic acid release in rat pituitary cells. Mol. Cell. Endocrinol. 57:157-162.

43. Ikeda, H., T. Mitsuhashi, K. Kubota, N. Kuzuya, and H. Uchimura. 1984. Epidermal growth factor stimulates growth hormone secretion from superfused rat adenohypophyseal fragments. Endocrinology. 115:556-558.

44. Logsdon, C.D. 1986. Stimulation of pancreatic acinar cell growth by CCK, epidermal growth factor, and insulin in vitro. Am. J. Physiol. 251:G487G494.

45. Bandyopadhyay, G.K., W. Imagawa, D.R. Wallace, and S. Nandi. 1988. Proliferative effects of insulin and epidermal growth factor on mouse mammary epithelial cells in primary culture. J. Biol. Chem. 263:7567-7573.

46. Logsdon, C.D., J. Moessner, J.A. Williams, and I.D. Goldfine. 1985. Glucocorticoids increase amylase mRNA levels, secretory organelles, and secretion in pancreatic acinar AR42J cells. J. Cell Biol. 100:1200-1208.

47. Singh, J. 1983. Effects of amino acids, glucagon, insulin and acetylcholine on cyclic nucleotide metabolism and amylase secretion in isolated mouse pancreatic fragments. Biochem. Pharmacol. 32:2017-2023.

48. Soling, H.D., and K.O. Unger. 1972. The role of insulin in the regulation of amylase synthesis in the rat pancreas. Eur. J. Clin. Invest. 2:199-212.

49. Singh, J. 1985. Mechanism of action on acetylcholine-evoked amylase secretion in the mouse pancreas. J. Physiol. (Lond.). 358:469-482. 